\title{
Platelet Rich Plasma: Is it Effective in Treatment of Atrophic Scar?
}

\author{
HAFSA G.M., M.Sc.*; AHMED KAMAL, M.D.*; HEBA M. SAAD ELDIEN, M.D.** and \\ MAHMOUD A. ELOTEIFY, M.D.*
}

The Departments of Plastic Surgery* and Histology**, Faculty of Medicine, Assiut University

\begin{abstract}
Introduction: Atrophic scar is the result of decrease collagen production and matrix formation, that's why management of atrophic scar is challenging for plastic surgeons. PRP plays an important role in tissue regeneration during wound healing via release of growth factors that have an important role in the regulation and proliferation of mesenchymal and fibroblast cells, hence it increase collagen production and improve wound healing. The main goal of the article is to evaluate the efficacy and safety of autologous platelet-rich plasma (PRP) injections in improvement of atrophic scar.
\end{abstract}

Patients and Methods: Twenty patients with atrophic scar were included in this study at plastic surgery department, Assiut university hospital, in duration from July 2016 to February 2017. Mean age was $22.68 \pm 6.75$ years. Patients were randomly divided into 2 groups to allow equal distribution. Group 1 (control), underwent scar revision only. Group 2 (study), underwent scar revision, followed by immediately intradermal autologous Platelet rich plasma (PRP) injection at the edges of the wound. This was followed by PRP injection every month for the next five months. Patients with atrophic non pigmented scars at any region of the body were included. Any case with history of medical co-morbidities also was excluded. Scar width, Vancouver scar scale (VSS), surgeon assessment scar scale, patient assessment scar scale and complications, were the outcome measurements.

Results: Surgeon assessment scar scale, VSS, and patient assessment scar scale showed no significant difference ( $p$ value $<0.05$ ) between the two groups preoperative, while there was significant clinical improvement of the resulting scar in group II compared to group I six months postoperatively, No complications were noticed in both groups.

Conclusion: We conclude that intradermal injection of autologous PRP in an atrophic scar after its revision could be considered as a promising option for atrophic scar management as it improves wound healing process that appears in the improvement of clinical appearance of the scar.

Key Words: Atrophic scars - Platelet rich plasma - PRP Scar revision.

Level of Evidence: Level IV - Therapeutic study.

Disclosure: None of the authors has any commercial association or financial disclosure that might pose or create a conflict of interest with information presented in this article.

\section{INTRODUCTION}

Atrophic scar is the result of decrease collagen production and matrix formation, that's why many doctors are convinced that this type of scar is untreatable due to the damaged skin tissues and collagen destruction. Histologically, the skin has reduced thickness and loss of normal architecture [1].

Several practical questions arise when dealing with atrophic scar. The desire to have beautiful and healthy looking scar is considered the most common question for both genders at any age.

Since scar is the final common outcome of tissue repair in mammals, the goal is to have fine un-noticed scar by the mean of reaching a desired outcome of the healing process [2].

To solve the problem of atrophic scar, many researchers have proposed various methods of treatment including, Laser therapy, dermabrasion, silicon containing products, fillers, skin needling and surgical scar revision. Each has its benefits and drawbacks [3].

In the last few years there has been a growing interest in using platelet-rich plasma (PRP) in the field of plastic surgery. However, to the authors, best knowledge, very few publications can be found available in the literatures that discuss the issue of using PRP in management of atrophic scar.

Platelet-rich plasma (PRP) which developed from blood and consists of plasma with a platelet concentration above the baseline considers one of the recent methods which are characterized by high levels of growth factors that enhance wound healing $[4,5]$.

Platelet-rich plasma (PRP) contains abundant amount of growth factors that play an important 
role in wound healing, through stimulation of angiogenesis, re-epithelization, matrix formation, and re-modeling and is chemotactic and mitotic agents for fibroblasts and endothelial cells. Autologous PRP injection is a safe process, applicable even at outpatient clinic, repeatable and reproducible technique that doesn't require post injection precautions such as avoidance of sun exposure which may interfere with patient usual habits like laser therapy or dermabrasion [6].

The objective of the present study is to study the effect of autologous PRP injection in improvement of atrophic scar after scar revision.

\section{PATIENTS AND METHODS}

This work was authorized by the ethics committee of Faculty of Medicine, Assiut University. This study was carried out to find out the effect of PRP injection on atrophic scar. Informed consent from patients or their parents was obtained. This prospective study was conducted on 20 patients with atrophic scar in different regions of the body, who were presented at the outpatient clinic of plastic surgery department, Assiut university hospital, in the period from July 2016 to February 2017. Patients were classified into two equal groups. Group 1 (control), underwent scar revision only. Group 2 (study), PRP was injected immediately after scar revision. Followed-up the patients was at least for six months.

All cases were undergone simple scar revision under local anaethesia using $2 \%$ lidocaine. Inverted lambert subcutaneous sutures were done using 4/0 Polydioxanone (PDF). We used 6/0 Prolene (monofilament non-absorbable) in face and $4 / 0$ in limbs and abdomen to close skin. Stitches were removed after 5 days in scar face and after 10 days in scars at the limbs. The patients used topical steroid cream for 2 weeks, followed by topical silicon containing ointment twice during the day, and silicon containing patch during night.

The patient returned weekly for the first month then monthly for the next 5 months.

For study patients, PRP was immediately injected intradermal at the edges of the post revision wound (group II). The platelet rich plasma was obtained from the patients (autologous) before scar revision by:

$20 \mathrm{ml}$ of autologous whole blood is collected into tubes containing acid-citrate-dextrose (ACD) and centrifuged at $1000 \mathrm{~g}$ for 10 minutes in order to get PRP at the top of the test tube. The PRP is further centrifuged at $1500 \mathrm{~g}$ for 10 minutes in order to obtain a PC (platelet concentrate) with a platelet count 4.5 times higher than the baseline, and platelet-poor plasma (PPP). The PC (platelet concentrate) is preserved in a sterile container and then combined with human thrombin $(0.2 \mathrm{ml}$ per $\mathrm{mL}$ of PC) and calcium gluconate immediately prior to injection [7]. The $20 \mathrm{ml}$ of whole blood yields $2 \mathrm{ml}$ PRP.

Each group was analyzed statistically based on:

- Age.

- Sex.

- Site of the scar.

- Duration of the scar.

- Relation of the scar to lines of relaxed skin tension.

- Vancouver scar scale pre-operative and 6 months post-operative (Table 1).

- Patient scar scale pre-operative and 6 months post-operative (Table 2).

- Physician scar scale preoperative and 6 months post-operative (Table 2).

- Percent of scar width improvement:

- $<25 \%$ of scar width improvement means poor result.

- 25-<50\% scar width improvement means fair result.

$-50-<75 \%$ of the scar width improvement means good result.

$-75-100 \%$ of the scar width improvement means excellent result.

Table (1): Vancouver Scar Scale (VSS) [8].

\begin{tabular}{lll}
\hline Character of the scar & Scar characteristic & Score \\
\hline Vascularity & Normal & 0 \\
& Pink & 1 \\
& Red & 2 \\
& Purple & 3 \\
Pigmentation & Normal & 0 \\
& Hypopigmentation & 1 \\
Pliability & Hyperpigmentation & 2 \\
& Normal & 0 \\
& Supple & 1 \\
& Yielding & 2 \\
& Firm & 3 \\
Height & Ropes & 4 \\
& Contracture & 5 \\
& Flat & 0 \\
& $<2 \mathrm{~mm}$ & 1 \\
& $2-5 \mathrm{~mm}$ & 2 \\
& $>5 \mathrm{~mm}$ & 3 \\
\hline
\end{tabular}

Total score 
Low VSS means good result:

Table (2): Patient satisfaction scale [9].

\begin{tabular}{lccc}
\hline & \multicolumn{3}{c}{ Improvement Score } \\
\cline { 2 - 4 } & $\begin{array}{c}\text { Poor } \\
\text { (Grade I) }\end{array}$ & $\begin{array}{c}\text { Good } \\
\text { (Grade II) }\end{array}$ & $\begin{array}{c}\text { Excellent } \\
\text { (Grade III) }\end{array}$ \\
\hline Scar Shape & 1 & 2 & 3 \\
Scar Texture & 1 & 2 & 3 \\
Scar Color & 1 & 2 & 3 \\
Itching & 1 & 2 & 3 \\
Contracture & 1 & 2 & 3 \\
\hline
\end{tabular}

Physician or patient satisfaction scale was assessed by using a questionnaire of 3-point grade to assess shape, texture, color, itching and contracture (total score ranges from 5-15).

- 5-6 patient or physician satisfaction score means poor result.

- 7-10 patient or physician satisfaction score means good result.

- 11-15 patient or physician satisfaction score means excellent result.

The results of study group were identified and compared with control group according to these previous criteria.

\section{Statistical analysis:}

The statistical software SPSS version 17 was used for data analysis. The results were expressed as mean $\pm \mathrm{SD}$. The significance level was set as $p<0.05$.

\section{RESULTS}

This study was conducted on 20 patients who were presented to plastic surgery clinic, Assiut University Hospital. Age ranged from 10 to 30 years old with mean age was $22.68 \pm 6.75$ year old. $45 \%$ of cases were males and $55 \%$ were females. Simple scar revision was done for the ten control patients (group I), and immediate intradermal injection of PRP was done for the other ten study patients (group II) after scar revision followed by once monthly PRP injection at the edges of the scar for the following five months. Reassessment of the cases was done six months after scar revision.

\section{Demographic data of the studied cases:}

Age ranged from 10-30 years old. The mean age was $22.68 \pm 6.75$. Of these 20 patients; 9 were males while 11 were females. (Figs. 1,2).

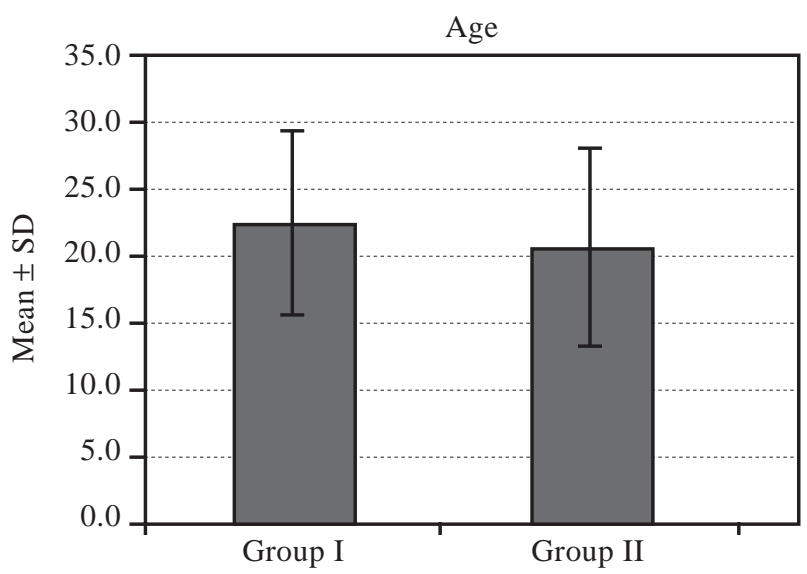

Fig. (1): Patient age distribution.

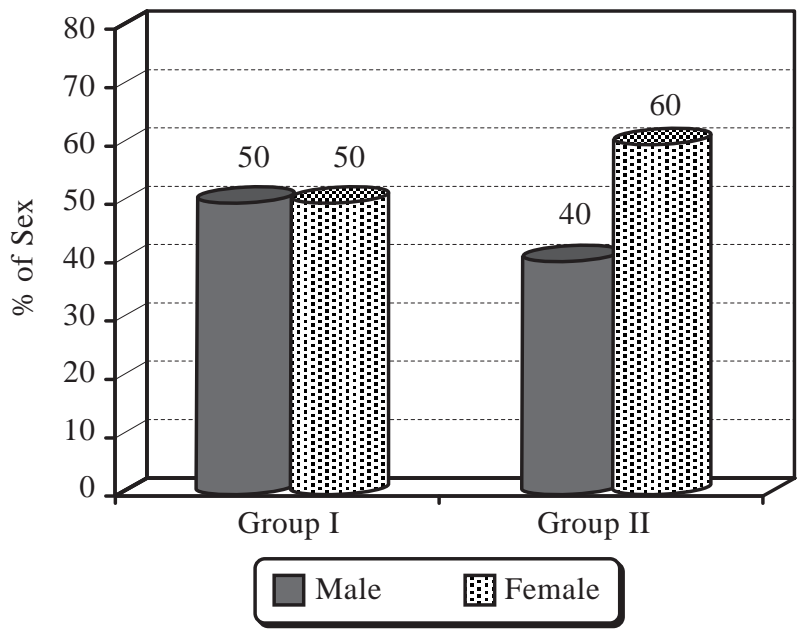

Fig. (2): Patient sex distribution.

Results of the atrophic scars assessments:

- Site of scar:

14 cases $(70 \%)$ have scar in their face, 4 patients (20\%) have scar in their lower limbs and 2 cases $(10 \%)$ have scar in their abdomen. No significant correlation between site of the scar and the results could be detected. (Fig. 3).

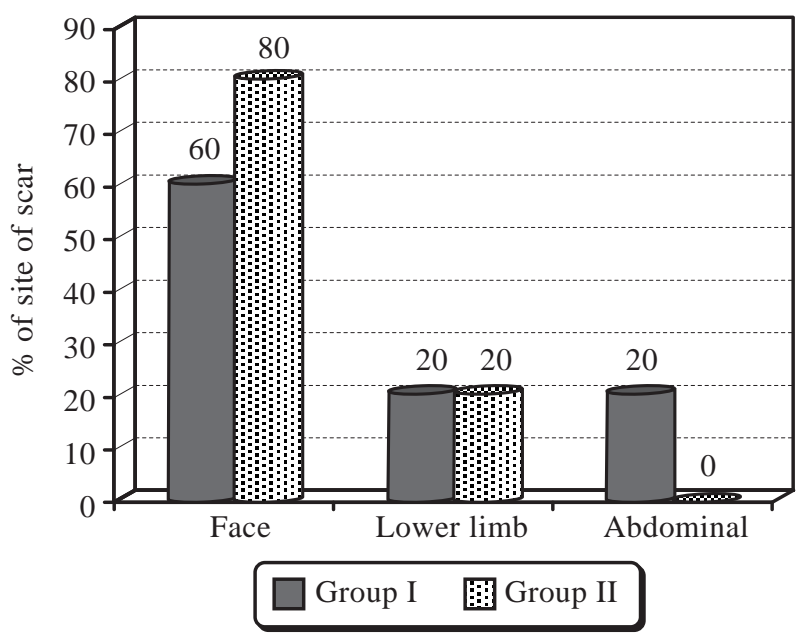

Fig. (3): Scar site distribution. 
- Etiology of the scar:

Post traumatic scar were in 12 patients while post-operative scar were in 8 cases. (Fig. 4).

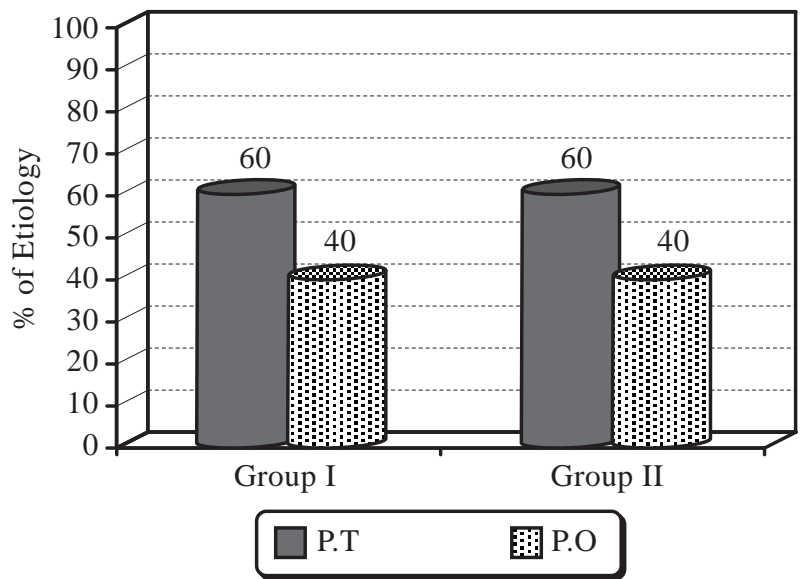

Fig. (4): Etiology of the scar.

- Duration of the scar:

Duration of the scar ranged from 1-5 years with mean $2.5 \pm .8$ years. (Fig. 5).

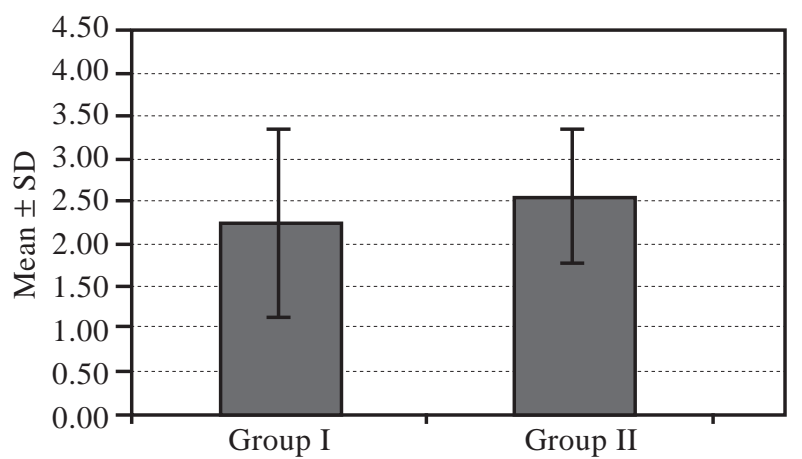

Fig. (5): Duration of the scar.

- Relation of the scar to lines of Langer:

Seven patients $(70 \%)$ in each group have scar parallel to Linger lines while the remaining 3 cases $(30 \%)$ in control and study groups have scar against Linger lines. (Fig. 6).

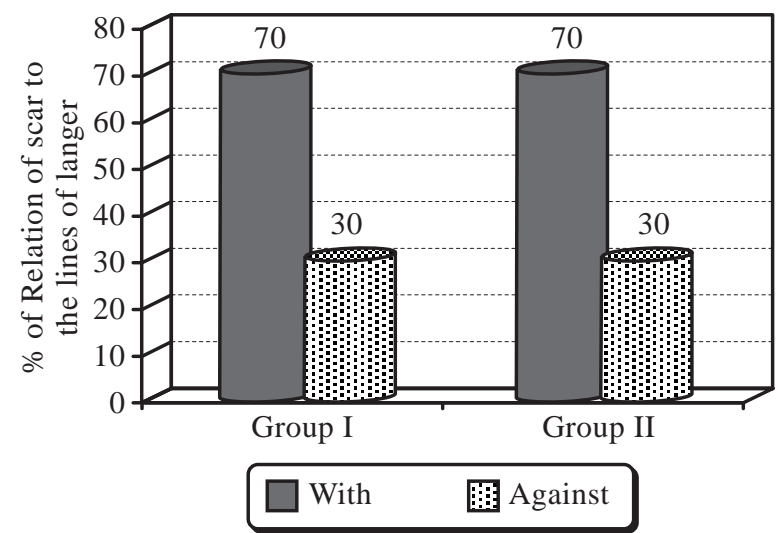

Fig. (6): Relation of the scar to lines of Langer.

\section{- Vancouver scar scale assessment:}

The Vancouver Scar Scale, the most widely used assessment scale which measures vascularity, pigmentation, pliability and height.

\section{A- In group I:}

VSS ranged from 4 to 9 with a mean $5.9 \pm 1.7$ pre operatively, while VSS ranged from 3 to 6 with a mean $4 \pm 0.9$ post operatively.

\section{B- Group II:}

VSS ranged from 4 to 8 with a mean $5.3 \pm 1.3$ pre operatively, while VSS ranged from 1 to 2 with a mean $1.6 \pm 0.5$ post operatively.

There was statistically significant difference between pre and 6 months post-operative in both control and study groups, $p$-value $<0.001$ (Table $3)$.

Table (3): Comparison between control and study groups' regards VSS pre-operative and six months postoperative.

\begin{tabular}{llll}
\hline VSS & Group I & Group II & $p$-value \\
\hline Pre-operative: & & & \\
$\quad$ Range & $4-9$ & $4-8$ & 0.234 \\
$\quad$ Mean \pm SD & $5.9 \pm 1.7$ & $5.3 \pm 1.3$ & \\
After 6 months: & & & \\
$\quad$ Range & $3-6$ & $1-2$ & $<0.001^{* *}$ \\
$\quad$ Mean \pm SD & $4 \pm 0.9$ & $1.6 \pm 0.5$ & \\
\hline
\end{tabular}

VSS six months post-operative showed highly significant improvement in the group treated with PRP compared to control group (Table 4).

Table (4): Comparison between control and study groups as regards VSS 6 months post operative.

\begin{tabular}{lcc}
\hline & Group I & Group II \\
\hline VSS after 6-months & $4 \pm 0.94$ & $1.6 \pm 0.52$ \\
$p$-value & & $<0.001^{* *}$ \\
\hline
\end{tabular}

- Response of atrophic scar to treatments according to patient scar assessment scale:

Group I:

Patient scar assessment scale ranged from 5 to 9 with a mean $7.9 \pm 1.2$, pre operatively, while 6 months post-operative, patient scar scale ranged from 8 to 11 with a mean $9.7 \pm 0.9$.

\section{Group II:}

Patient scar assessment scale ranged from 7 to 9 with a mean $8.2 \pm 0.6$, pre operatively, while 6months post-operative, patient scar scale ranged from 11 to 14 with a mean $12.3 \pm 1.1$. 
There was statistically significant difference between pre and 6 months post-operative in both control and study groups, $p$-value $<0.001$ (Table $5)$.

Table (5): Comparison between control and study groups regards Patient Scar Assessment scale pre-operative and six months post-operative.

\begin{tabular}{llll}
\hline $\begin{array}{l}\text { Patient Scar } \\
\text { Assessment scale }\end{array}$ & Group I & Group II & $p$-value \\
\hline $\begin{array}{l}\text { Pre-operative: } \\
\quad \text { Range }\end{array}$ & $5-9$ & $7-9$ & 0.401 \\
$\quad$ Mean \pm SD & $7.9 \pm 1.2$ & $8.2 \pm 0.6$ & \\
$\begin{array}{l}\text { After } 6 \text { months: } \\
\quad \text { Range }\end{array}$ & $8-11$ & $11-14$ & $<0.001^{* *}$ \\
$\quad$ Mean \pm SD & $9.7 \pm 0.9$ & $12.3 \pm 1.1$ & \\
\hline
\end{tabular}

Patient assessment scar scale showed significant improvement in cases of group II in comparison with those of group I.

There was statistically significant difference between control and study groups, $p<0.001$ (Table $6)$.

Table (6): Comparison between control and study groups regards Patient Scar Assessment scale 6 months post-operative.

\begin{tabular}{lcc}
\hline & Group I & Group II \\
\hline $\begin{array}{l}\text { Patient Scar Assessment } \\
\text { scale 6 months post-operative }\end{array}$ & $9.7 \pm 0.95$ & $12.3 \pm 1.06$ \\
$p$-value & & $<0.001 * *$ \\
\hline
\end{tabular}

- Response of atrophic scar to treatments according to physician scar assessment scale:

Group I:

Physician scar assessment scale ranged from 7 to 10 with a mean $9 \pm 1.1$ pre-operative. While 6 months post-operative, it ranged from 9 to 12 with a mean $10.4 \pm 1.1$.

\section{Group II:}

Physician scar assessment scale was ranged from 8 to 11 with a mean $8.9 \pm 1$, pre-operative, while 6-months post-operative, it ranged from 11 to 14 with a mean $12.4 \pm 1.2$.

There was statistically significant difference between pre and 6 months post-operative in both control and study groups, $p$-value $<0.001$ (Table 7).
Table (7): Comparison between control and study groups regards Physician Scar Assessment scale preoperative and six months post-operative.

\begin{tabular}{llll}
\hline $\begin{array}{l}\text { Physician } \\
\text { scar scale }\end{array}$ & Group I & Group II & $p$-value \\
\hline $\begin{array}{l}\text { Pre-operative: } \\
\quad \text { Range }\end{array}$ & $7-10$ & $8-11$ & 0.633 \\
$\quad$ Mean \pm SD & $9 \pm 1.1$ & $8.9 \pm 1$ & \\
After 6 months: & & & \\
$\quad$ Range & $9-12$ & $11-14$ & $<0.001^{* *}$ \\
$\quad$ Mean \pm SD & $10.4 \pm 1.1$ & $12.4 \pm 1.2$ & \\
\hline
\end{tabular}

Table (8): Comparison between control and study groups regards Physician Scar Assessment scale 6 months post-operative.

\begin{tabular}{lcc}
\hline & Group I & Group II \\
\hline $\begin{array}{l}\text { Physician scar Assessment } \\
\text { scale 6 months post-operative }\end{array}$ & $10.4 \pm 1.07$ & $12.4 \pm 1.17$ \\
$p$-value & & $<0.001^{* *}$ \\
\hline
\end{tabular}

This table shows that physician assessment scar scale showed significant improvement in cases of group II in comparison with those of group I.

- According to improvement of scar width:

Pre and post op. measurements of scar width were taken and the percent of improvement of scar width was calculated for each group:

- Group I: Percent of improvement of scar width ranged from 10-40\% with Mean \pm SD 26.5 \pm 11.6 .

- Group II: Percent of improvement of scar width range from $50-70 \%$ with Mean \pm SD 61 \pm 7.4 .

There was statistically significant difference between pre-operative and post-operative in groups I and II (Table 9).

Table (9): Comparison between control and study groups regards Percent of improvement of scar width 6 months post-operative.

\begin{tabular}{llll}
\hline & Group I & Group II & $p$-value \\
\hline $\begin{array}{l}\text { Percent of improvement } \\
\text { of scar width: }\end{array}$ & & & \\
$\quad$ Range & $10-40$ & $50-70$ & $<0.001 * *$ \\
$\quad$ Mean \pm SD & $26.5 \pm 11.6$ & $61 \pm 7.4$ & \\
\hline
\end{tabular}

Table (10): Comparison between control and study groups regards percent of improvement of scar width six months post-operative, according to relation of scar to lines of Langer.

\begin{tabular}{llll}
\hline & Group I & Group II & $p$-value \\
\hline With & $28.57 \pm 9.88$ & $64.29 \pm 5.35$ & $<0.001^{* *}$ \\
Against & $21.67 \pm 16.07$ & $53.33 \pm 5.77$ & $0.003^{* *}$ \\
\hline
\end{tabular}


There was statistically significant improvement of scar width in PRP group compared to control group post-operative in atrophic scars regardless with or against Langer lines but the improvement was better in scars parallel than against Langer lines (Table 10).

\section{Clinical Cases:}
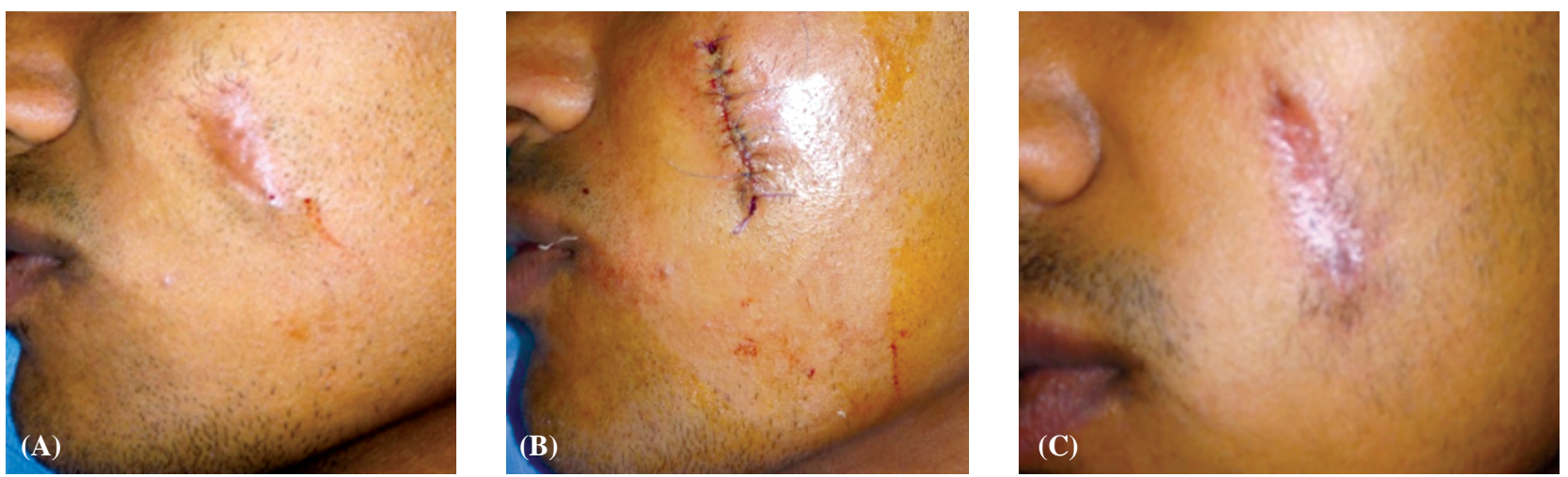

Fig. (7): Male patient 30 years old have post traumatic scar at the left check parallel to lines of Langer, since 1y. (A) Preoperative, (B) Immediately after scar revision, (C) 6-months post-operative shows about $20 \%$ improvement of the width of the scar, no improvement of color of the scar and poor patient satisfaction.
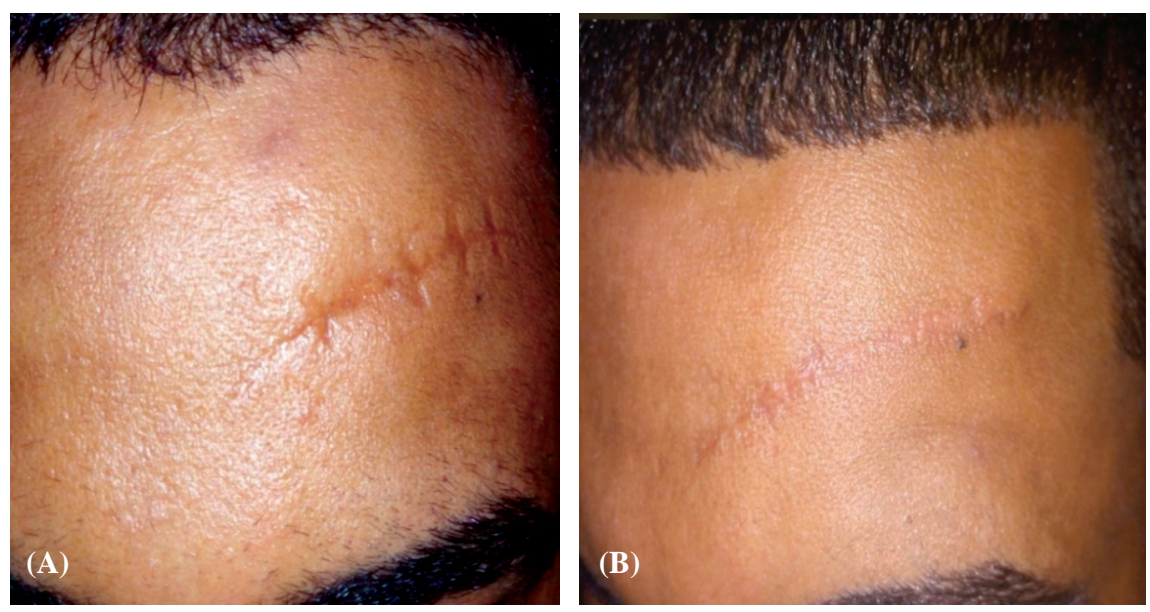

Fig. (8): Male patient 25 years old have post traumatic forehead scar parallel to lines of Langer since 5y. (A) Pre-operative, (B) 6-months postoperative showing $60 \%$ improvement of the scar width, flattening of the depression of the scar and excellent patient satisfaction.
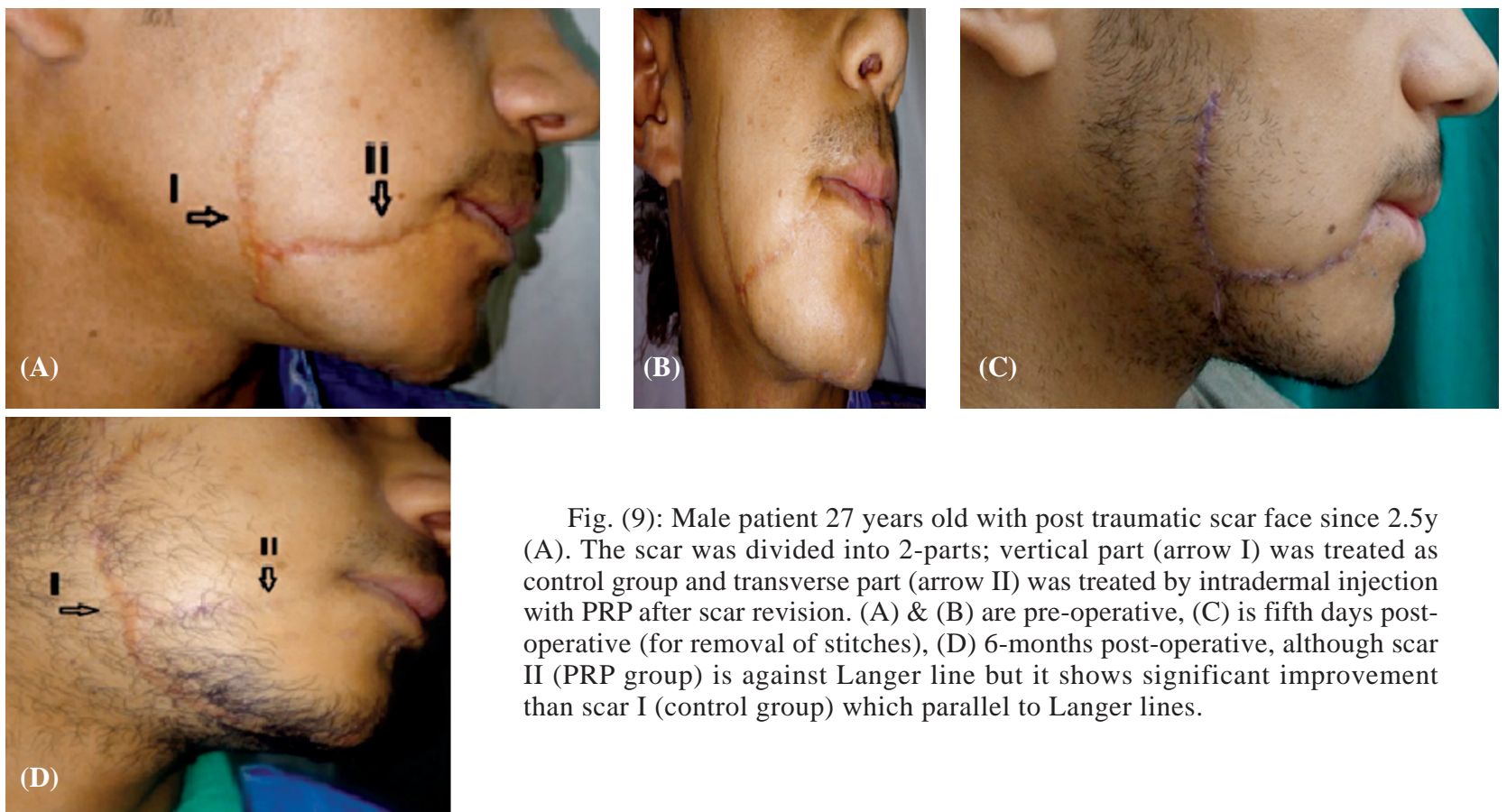

Fig. (9): Male patient 27 years old with post traumatic scar face since $2.5 y$ (A). The scar was divided into 2-parts; vertical part (arrow I) was treated as control group and transverse part (arrow II) was treated by intradermal injection with PRP after scar revision. (A) \& (B) are pre-operative, (C) is fifth days postoperative (for removal of stitches), (D) 6-months post-operative, although scar II (PRP group) is against Langer line but it shows significant improvement than scar I (control group) which parallel to Langer lines. 


\section{DISCUSSION}

Despite many modern techniques use to improve scars, there is still a need for other new methods to improve the atrophic scars results after their surgical revision. One of the promising new methods is injection of PRP to improve the clinical appearance of atrophic scar.

Quite recently, considerable attention has been paid to use autologous platelet-rich plasma (PRP) for a wide variety of surgical applications, particularly in cosmetic surgery.

Few studies were conducted for assessing the effect of intradermal PRP injection on improvement of non-acne - atrophic scars.

The purpose of this study is to evaluate the efficacy and safety of intradermal autologous platelet-rich plasma (PRP) injection in improvement of atrophic scar.

Several publications have been appeared in recent years documenting that autologous PRP has minimal scar tissue formation or serious side effects [10].

The results of this study are in good agreement with other studies which have shown that PRP clinically improve the appearance of atrophic scar which indicate minimal scar tissue formation, with no significant adverse effect.

Platelets contain large stores of growth factors and the effectiveness of PRP is based on these growth factors such as PDGF, EGF, and TGF that have an important role in matrix and new healthy tissue formation, and stem cells proliferation $[11,12,13]$.

The data obtained from this study shows significant improvement of clinical appearance of atrophic scar as regard Vancouver scar scale, patient assessment scar scale, physician assessment scar scale and percent of improvement of scar width, after intradermal injection of PRP following revision, compared to surgical revision only. This may be due to high contents of platelets in PRP which release growth factors that promote cellular proliferation, matrix formation and collagen production. Hence it directs the issue of decreased collagen synthesis (mechanism of atrophic scaring).

On a split-face, randomized clinical trial is conducted by Faghihi et al., in 2016 [14] to study the efficacy of autologous platelet-rich plasma combined with fractional ablative carbon dioxide resurfacing laser in treatment of facial atrophic acne scars, He conclude that patients, satisfaction is higher on the side of the face that is treated with the combination of PRP and fractional ablative $\mathrm{CO} 2$ laser than on the side that is treated with fractional ablative $\mathrm{CO} 2$ laser only.

Lee et al., reported [15], that patients who receive ablative fractional carbon dioxide laser combined with intradermal platelet-rich plasma injection on one half of the face have significant improvement in clinical appearance of scar and erythema is improved faster than the other side which receive fractional carbon dioxide laser combined with intradermal normal saline injection.

The findings from the present study support a previously accepted hypothesis that there are higher patients and physicians' satisfaction and clinical improvement of atrophic scar after injection of PRP following surgical revision than revision only but we did not use laser.

Spiridaskin et al., reported [16] that using platelet derived growth factor (PDGF) enhances the healing process of pilonidal sinus and shorten patients, recovery period. On contrary, Litmath et al. [17] reported that, there is no significant effect of using autologous platelet rich gel on healing of complicated wounds on high risk patients. In contrast to some reports in the literature, the results from the presenting study show significant improvement of uncomplicated atrophic scars in completely fit patients who are injected by PRP compare to control patients.

The results of this study are in good agreement with other studies [18] which have shown that second, third, and fourth decade are the common age seeking for scar revision.

We didn't meet any limitation during the study as PRP is easy obtainable, applicable and safe repeatable maneuver.

The next stage of our research will be studying the effect of intradermal PRP injection on atrophic scar without revision.

We also recommend further studying the effect of PRP injection on other types of scars and the effect of its injection at subcutaneous instead of intradermal level. We also recommend further studying the histological point of view beside the clinical results to know the exact mechanism by which the PRP improves the appearance of scar.

Our study suggests that injecting a recent wound with PRP will result in desirable outcome of wound healing and scaring. 


\section{Conclusion:}

From the research that has been carried out, it is possible to conclude that intradermal injection of autologous PRP in an atrophic scar after its revision could be considered as a promising option for atrophic scar management as it improves wound healing process and decreases scar tissue formation that appears in the improvement of clinical appearance of the scar.

\section{REFERENCES}

1- Chen M.A. and Davidson T.M.: Scar management: Prevention and treatment strategies. Curr. Opin. Otolaryngol. Head Neck Surg., 13: 242-249, 2005.

2- Charkoudian N.: Skin blood flow in adult human thermoregulation: How it works, when it works, when it does not, and why. Mayo Clinic Proceedings, 78 (5): 603-612, 2003.

3- Mostafa Pour S.P. and C.S. Murakami: "Tissue Expansion and Serial Excision in Scar Revision". Facial Plastic Surgery, 17: 245-252, November 2001.

4- Mei-Dan O., Laver L., Nyska M. and Mann G.: Platelet rich plasma-a new biotechnology for treatment of sports injuries. Harefuah, 150: 453-460, 2011.

5- Nurden A.T.: Platelets, inflammation and tissue regeneration. Thromb Haemost, 105 (Supple 1): 13-33, 2011.

6- Senzel L., Gnatenko D.V. and Bahou W.F.: The platelet proteome. Curr. Opin. Hematol., 5: 329-233, 2009.

7- Lorenz H.P. and Longaker M.T.: Wound healing: Repair biology and wound and scar treatment. In: Mathes S.J., ed. Plastic surgery. Philadelphia: Saunders Elsevier, 1: 209-241, 2006.

8- Nedelec B., Shankowsky H.A. and Tredget E.E.: Rating the resolving hypertrophic scar: Comparison of the Vancouver Scar Scale and scar volume. Journal of Burn Care \& Research, 21 (3): 205-hyhen, May 1, 2000.

9- Draaijers, Lieneke J.F.R., Botman Y.A., Tuinebreijer W.E., Middelkoop E., Kreis R.W. and van Zuijlen P.: The patient and observer scar assessment scale: a reliable and feasible tool for scar evaluation. Plastic and reconstructive Surgery; 113.7: 1960-1965, 2004

10- Casabona F., Priano V., Vallerino V., et al.: New surgical approach to lichen sclerosus of the vulva: The role of adipose-derived mesenchymal cells and platelet-rich plasma in tissue regeneration. Plast. Reconstr. Surg., 126: 210e-211e, 2010.

11- Sarvajnamurthy S., Suryanarayan S., Budamakuntala L., et al.: Autologous platelet rich plasma in chronic venous ulcers: study of 17 cases. J. Cutan Aesthetic Surg., 6: 97 99, 2013.

12- Yotsu R.R., Hagiwara S., Okochi H., et al.: Case series of patientswith chronic foot ulcers treated with autologous platelet-rich plasma. J. Dermatol., 42: 288-295, 2015.

13- Wesner M., Defreitas T., Bredy H., et al.: A pilot study evaluating the effectiveness of platelet-rich plasma therapy for treating degenerative tendinopathies: A randomized control trial with synchronous observational cohort. PLoS One, 11: e0147842 2016.

14- Faghihi G., Keyvan S., Asilian A., Nouraei S., Behfar S and Nilforoushzadeh M.A.: Efficacy of autologous plateletrich plasma combined with fractional ablative carbon dioxide resurfacing laser in treatment of facial atrophic acne scars: A split-face randomized clinical trial. Indian J Dermatol Venereol Leprol [serial online] 2016 [cited Sep 24]; 82:162-170. Available from: http://www.ijdvl. com/text.asp?2016/82/2/162/174378, 2017

15- Lee J.W., Kim B.J., Kim M.N. and Mun S.K.: The efficacy of autologous platelet rich plasma combined with ablative carbon dioxide fractional resurfacing for acne scars: A simultaneous split-face trial. Dermatol. Surg., 37: 931939, 2011.

16- Spyridaki I.S., Skevaki C.L., Christodoulou I., Tiniakou I., Georgiou V. and Xepapadaki: Budesonide and formoterol inhibit inflammatory mediator production by bronchial epithelial cells infected with rhinovirus. Clinical \& Experimental Allergy, 39.11: 1700-1710, 2009.

17- Litmath J., et al.: Predictors and outcome of ICU readmission after cardiac surgery. The Thoracic and cardiovascular surgeon, 57.07: 391-394, 2009.

18- Ghadishah D. and J. Gorchynski: "Airway Compromise after Routine Alpha-Hydroxy Facial Peel Administration." Journal of Emergency Medicine, 22: 353-358, May, 2004. 